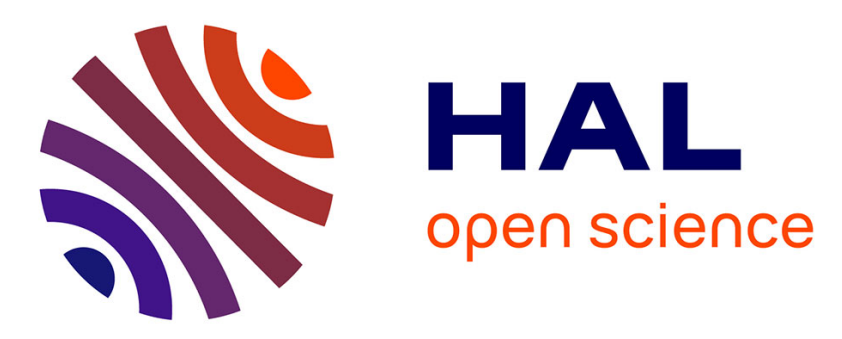

\title{
A supramolecular chain of dimeric Dy single molecule magnets decorated with azobenzene ligands
}

Gang Huang, Xiaohui Yi, Frédéric Gendron, Boris Le Guennic, Thierry Guizouarn, Carole Daiguebonne, Guillaume Calvez, Yan Suffren, Olivier Guillou, Kevin Bernot

\section{To cite this version:}

Gang Huang, Xiaohui Yi, Frédéric Gendron, Boris Le Guennic, Thierry Guizouarn, et al.. A supramolecular chain of dimeric Dy single molecule magnets decorated with azobenzene ligands. Dalton Transactions, 2019, 48 (42), pp.16053-16061. 10.1039/c9dt03540k . hal-02364866

\section{HAL Id: hal-02364866 https://hal-univ-rennes1.archives-ouvertes.fr/hal-02364866}

Submitted on 17 Feb 2020

HAL is a multi-disciplinary open access archive for the deposit and dissemination of scientific research documents, whether they are published or not. The documents may come from teaching and research institutions in France or abroad, or from public or private research centers.
L'archive ouverte pluridisciplinaire HAL, est destinée au dépôt et à la diffusion de documents scientifiques de niveau recherche, publiés ou non, émanant des établissements d'enseignement et de recherche français ou étrangers, des laboratoires publics ou privés. 


\section{A supramolecular chain of dimeric Dy single molecule magnets decorated with azobenzene ligands}

Gang Huang, ${ }^{a}$ Xiaohui Yi, ${ }^{a}$ Frederic Gendron, ${ }^{a}$ Boris Le Guennic, ${ }^{a}$ Thierry Guizouarn, ${ }^{\text {a }}$ Carole Daiguebonne, ${ }^{a}$ Guillaume Calvez, ${ }^{a}$ Yan Suffren, ${ }^{a}$ Olivier Guillou ${ }^{a}$ and Kevin Bernot ${ }^{*}$

We report on the synthesis, ab-initio calculations, magnetic and optical characterization of a Dy'l'-based dimeric compound named DyAzo. The dimers self-organize into a supramolecular chain decorated with photo-isomerizable azobenzene ligands. DyAZO displays a Single-Molecule Magnet (SMM) behavior. However, ab-initio calculations highlight a quite strong admixture of $M_{\jmath}$ states of the ${ }^{6} \mathrm{H}_{15 / 2}$ level of the Dy ${ }^{\text {III }}$ ions, the presence of low-lying excited $\mathrm{M}$, states as well as an antiferromagnetic Dy-Dy dipolar coupling. This favors zero-field fast tunneling. Accordingly the Dy-doped analogue YDyAZO (5.5\% Dy doping) displays an enhanced magnetic relaxation with an hysteresis that is observed at $0.5 \mathrm{~K}$. The influence on the magnetic properties of the decorating azobenzene ligand cis- to trans- isomerization has been tested both on solid samples and solutions of DyAZO and YDyAZO. This provides hints for the synthesis of future Dy-based photo-isomerizable molecules.

a. Univ Rennes, INSA Rennes, CNRS, ISCR (Institut des Sciences Chimiques de Rennes), UMR 6226, F 35000 Rennes, France.

\section{Introduction}

Single-molecule magnets (SMMs) are molecules able to retain magnetic information at the molecular scale. ${ }^{1-4}$ However for more than twenty years, their magnetic and quantic properties were confined to very low temperature. Recently, considerable improvements of their working temperature have been observed thanks to the rational design of lanthanide-based SMMs (Ln-SMMs). ${ }^{5-7}$

However, small perturbations in the electrostatic surrounding of $\mathrm{Ln}-S M M s^{8-12}$ are known to induce drastic changes in their magnetic behavior. ${ }^{13-20}$ This is particularly true for lanthanide dimers where both exchange and dipolar couplings are mixed. ${ }^{21-27}$ Such influence of electrostatic on the magnetic relaxation of SMM behavior was rationalized recently ${ }^{16,28-31}$ but full control of this feature in a given molecule is relatively hard to achieve. Indeed, reversible modification of the electrostatic surrounding of a given Ln-SMM could allow observing tailored changes in its magnetic relaxation.

SMM switching was observed on various $3 \mathrm{~d}$ complexes and triggered for example by solvatation/desolvatation processes, $^{32,33}$ valence tautomerism ${ }^{34}$, metal-to-metal charge transfer, ${ }^{35}$ combination with spin-crossover, ${ }^{36}$ light-induced molecular motion, ${ }^{37}$ light-induced electron transfer, ${ }^{38}$ or on a remarkable example of $3 \mathrm{~d}-4 \mathrm{f}$ SMM redox switch. ${ }^{39}$ Last, photochromic ligands have been also reported to be efficient to influence SMM properties on 3d-SMM. ${ }^{40,41}$

SMM switching of $4 \mathrm{f}-\mathrm{SMM}$ is trickier but was observed using solvatation/desolvatation processes, ${ }^{42,}{ }^{43}$ liquid-crystal phase transitions ${ }^{44}$, redox $4 \mathrm{~d}-4 \mathrm{f}$ switch $^{45}$ or photochromic ligands such as merocyanine ${ }^{46}$ or diarylethene. ${ }^{47-49}$ Photochromic ligands are particularly interesting in combination with lanthanide ions because their photoconversion induces both an electrostatic change in the ion surrounding and a strong molecular motion in the crystal packing that can in some cases, goes up to single-crystal to single-crystal transformation. ${ }^{50}$ In this work, we focused our efforts on photochromic ligands of the azobenzene family. In fact, azobenzene derivatives can be switched easily from their trans to cis form by UV light. ${ }^{51,52}$ Efficient azobenzene switching is also reported in the solid-state even when grafted on surface. ${ }^{53-56}$ Azobenzene ligands are used most of the time to build fully organic compounds with molecular switching properties ${ }^{51}$ and mainly in order to trigger molecular motion. ${ }^{57-59}$ Some examples of metal complexes ${ }^{57,58,60-66}$ or metal-organic frameworks ${ }^{67}$ decorated with azobenzene-like molecules ${ }^{68}$ are reported but very few regarding $4 \mathrm{f}$ complexes. ${ }^{69,70}$

This is the reason why we reacted an optically active azobenzene-like ligand (4-(Phenylazo)benzoic sodium salt, latter named "AZO") that is able to bind Dy" ions via its carboxylate clamp, to dysprosium chloride. A dimer is obtained that forms a supramolecular chain of formula $\left\{\left[\mathrm{Dy}_{2} \mathrm{AZO}_{6} \mathrm{DMSO}_{2}\left(\mathrm{H}_{2} \mathrm{O}\right)_{2}\right] \cdot \mathrm{DMSO}_{2}\right\}_{\mathrm{n}}$ (latter called DyAZO) via an $\mathrm{H}$-bonds network. DyAZO and its yttrium-doped analogue (YDyAzO) are fully characterized on the structural and magnetic point of view. Optical and magnetic investigations of the photoswitched derivatives are performed on the solution and solid-states.

\section{Results and discussion}

\section{Crystal structure description}

DyAZO is obtained as big orange needles (see experimental section). It crystallizes in the $P-1\left(\mathrm{~N}^{\circ} 2\right)$ space group (Table $\left.\mathrm{S} 1\right)$. The asymmetric unit is made of one Dy atom (Dy1) that is bound to three AZO ligands (two chelating and one bridging), one $\mathrm{H}_{2} \mathrm{O}$ molecule and one DMSO molecule. Two free DMSO molecules complete the asymmetric unit (Figure 1). In details, 
each Dy ${ }^{\prime \prime \prime}$ ion is coordinated by eight oxygen atoms: four oxygen atoms (02, 05, 07 and 09) from two carboxylate clamps of two AZO ligands (acting as bidentate ligands) and two other oxygen atoms $(01,08)$ from two AZO ligands (acting as bridging ligands). Finally, the coordination polyhedron of Dy1 is completed by one water molecule (O3) and one DMSO molecule (O4). The Dy-O distances are in the 2.27(17)-2.48(18) $\AA$ range (Table S2). The coordination polyhedron symmetry is determined by Continuous Shape Measurement $(\mathrm{CShM})^{71}$ as a very distorted bi-augmented trigonal prism $\left(C_{2 v}\right)$ with $\mathrm{CShM}=2.374$ (Figure S1, Table S3). A dimeric unit is formed with a quite short Dy-Dy distance of $4.58(21) \AA$.

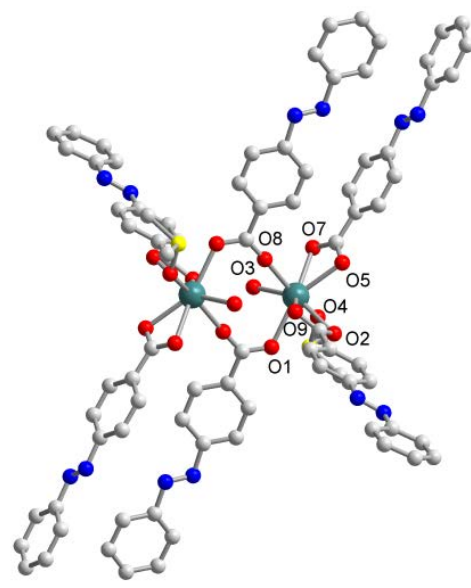

Figure 1. Representation of the dimer found in DyAzO (Dy, teal; O, red; $\mathrm{C}$, grey; $\mathrm{N}$, blue; $\mathrm{S}$, yellow). Hydrogen atoms and free solvent molecules omitted for clarity.

The AZO ligands are almost flat and the angle between the aromatic groups that belong to the same ligand are $3.77^{\circ}$, $6.38^{\circ}$ and $13.47^{\circ}$. The $\mathrm{C}-\mathrm{N}$ and $\mathrm{N}-\mathrm{C}$ bonds are almost parallel with torsion angles below $0.82^{\circ}$ for C24N3-N4C42, C43N6-N5C30 and C34N1-N2C59, respectively (Figure S2). The AZO ligands are thus found in their trans-configuration. The bridging AZO ligands interacts with the chelating ones through intramolecular point-to-face $\mathrm{CH}-\pi$ interactions. ${ }^{72}$ The distances between the calculated position of the $\mathrm{H}$ atom and the centroid of the aromatic rings are 3.39(1) $\AA$ and 3.10(2) $\AA$ for the first and second ring, respectively.

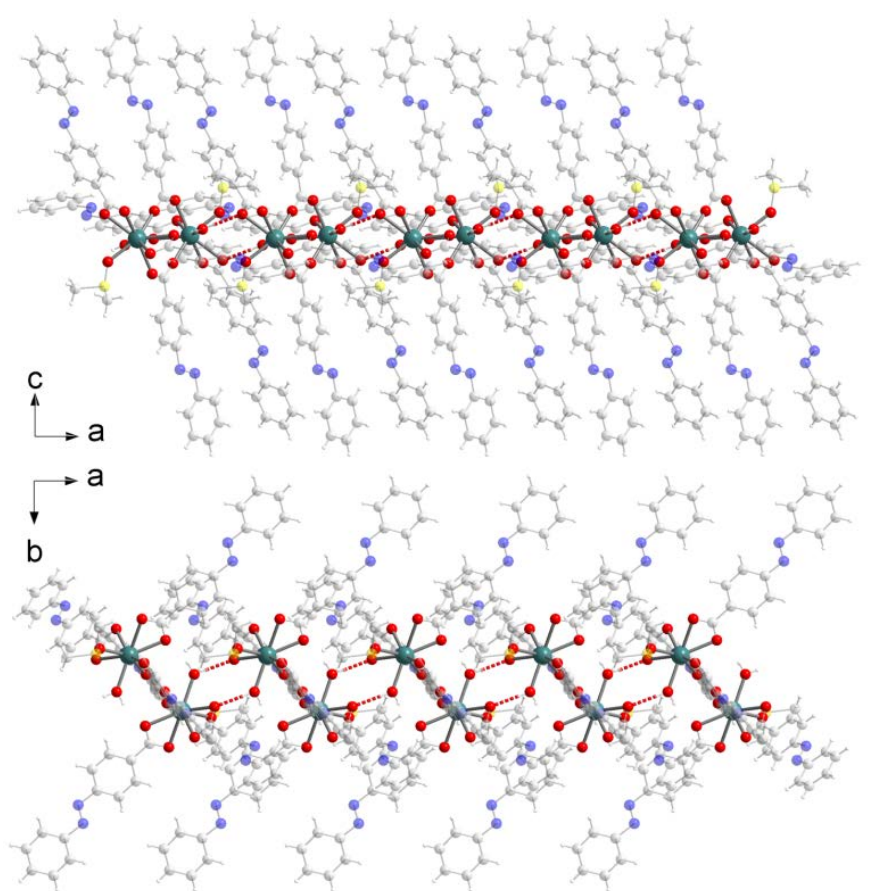

Figure 2. Representation of the supramolecular chain in DyAZO along the $\mathrm{b}$ (top) and $\mathrm{c}$ axis (bottom). Intermolecular $\mathrm{H}$ bonds as red dashed bonds. Free solvent molecules omitted for clarity.

The AZO ligands that are not involved in the point-to-face $\mathrm{CH}-\pi$ interactions $^{72}$ give intermolecular face-to-face $\pi-\pi$ interactions ${ }^{72}$ with the respective ligand of the neighboring dimer (Figure S3). The average distance between the centroids of the aromatic rings is 3.63 (1) Å. The crystal packing shows also hydrogen bonds between the coordinated water molecule (O3) of one dimer and oxygen atoms (O7) of the neighbor (Figures 2 and S4). The overall picture is a chain of dimers connected by hydrogen bonds along the $a$ axis (Figure 2). Both $\pi-\pi$ interactions and hydrogen bonding network stabilize a chain-like supramolecular architecture. The shortest intermolecular Dy-Dy distance is 6.06 (2) A. Finally, two crystallization DMSO molecules are also found in the crystal packing and lie in between the pseudo-chains. The overall formula of DyAZO compound is then $\left\{\left[\mathrm{Dy}{ }_{2} \mathrm{AZO}_{6} \mathrm{DMSO}_{2}\left(\mathrm{H}_{2} \mathrm{O}\right)_{2}\right] \cdot \mathrm{DMSO}_{2}\right\}_{n}$.

In summary, DyAZO is a supramolecular chain of Dy $y^{\prime \prime \prime}$-dimers decorated with photo-isomerizable ligands.

\section{Static magnetic measurements}

The temperature dependence of the $\chi_{M} T$ product is depicted in Figure 3. At room-temperature, the value of $\chi_{M} T$ is $27.26 \mathrm{~cm}^{3} . \mathrm{K} \mathrm{mol}^{-1}$, slightly lower than the theoretical value of two non-interacting $\mathrm{Dy}^{\prime \prime \prime}\left({ }^{6} \mathrm{H}_{15 / 2}\right.$ ground state and $\mathrm{g}_{\mathrm{j}}=4 / 3$, $\left.\chi_{M} T=28.34 \mathrm{~cm}^{3} \cdot K \cdot \mathrm{mol}^{-1}\right)$. On cooling, the value of $\chi_{M} T$ decreases gradually and then drops rapidly below $50 \mathrm{~K}$. This behavior is due to the depopulation of the Stark sublevels of $\pm M$, states of the $\mathrm{Dy}^{\prime \prime \prime}$ ion, and/or the antiferromagnetic interactions between the $\mathrm{Dy}^{\prime \prime \prime}$ ions that can be either intramolecular and at a fewer extent intermolecular. ${ }^{1}$ The 
magnetization at $2 \mathrm{~K}$ and $50000 \mathrm{Oe}$ is close to $10 \mu_{\mathrm{B}}$ in line with what expected on a polycrystalline powder of Dy ${ }^{\text {III }}$-dimers. ${ }^{21,73,}$ 74
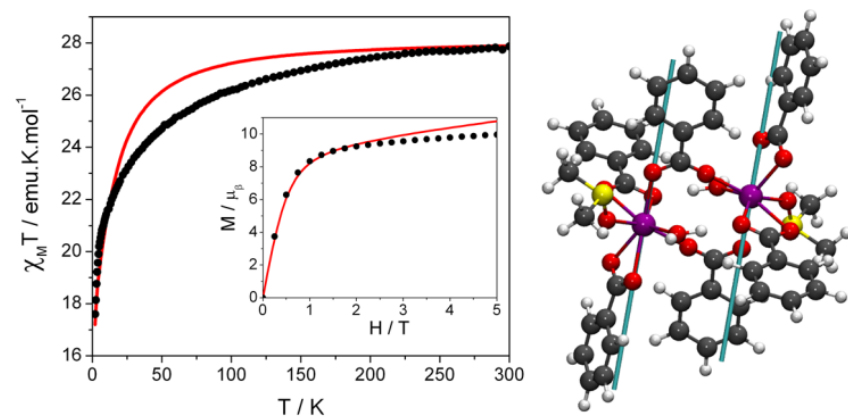

Figure 3. (left) Experimental (black dot) and calculated (red curve) temperature dependence of the $\chi_{M} T$ product for DyAzO and field dependence of the magnetization at $2 \mathrm{~K}$ in inset. (right) Orientation of the calculated easy magnetization axes for the ground state of the $\mathrm{Dy}^{3+}$ centers (Dy, teal; O, red; C, grey; N, blue; S, yellow).

\section{Ab initio calculation}

The electronic structure of DyAZO was further investigated with the help of multi-configurational wavefunction calculations (see computational details, Table S4, Figure S5). The nature of the ground state (GS) of the isolated $\mathrm{Dy}^{3+}$ centers results from a strong admixture by the crystal-field splitting of several $M_{J}$ states of the ${ }^{6} \mathrm{H}_{15 / 2}$ level. Indeed, the GS wavefunction of both centers corresponds to $66 \%$ of $M_{J}$ $=\mid \pm 15 / 2>, 15 \%$ of $\mid \pm 11 / 2>, 6 \%$ of $\mid \pm 7 / 2>$, and $5 \%$ of $\mid \pm 13 / 2>$ and $\mid \pm 9 / 2>$. This strong admixture leads to a large reduction of the magnetic anisotropy of the $\mathrm{Dy}^{3+}$ ions, characterized by the calculated EPR g-factors $\mathrm{g} \|=17.3$ and $\mathrm{g} \perp=0.4$. For comparison, a pure $M_{J}=15 / 2$ Kramers doublet would generate $\mathrm{g}||=20.0$ and $\mathrm{g} \perp=0.0$. A relatively small energetic splitting of $400 \mathrm{~cm}^{-1}$ is calculated for the entire ${ }^{6} \mathrm{H}_{15 / 2}$ level, with two very low-lying excited states (ES) calculated at 34 and $47 \mathrm{~cm}^{-1}$ above the GS (see Table S4). The presence of these two ES allows rationalizing the calculated static magnetic properties shown in Figure 3. Despite a proper description of both the nature of GS and of the total energetic splitting of the ${ }^{6} \mathrm{H}_{15 / 2}$ level, the presence of very low-lying ESs leads to a faster increase of the calculated $\chi_{M} T$ with the increase of the temperature, when compared to the experimental data. Such discrepancy between theory and experimental data is not uncommon and corresponds to small deviations in the calculated energies and compositions of the crystal-field states. ${ }^{75}$ At low temperature, the decrease of the $\chi_{M} T$ product is reinforced by a small intramolecular antiferromagnetic (AFM) interaction between the two $\mathrm{Dy}^{3+}$ ions. The calculated isotropic dipolar contribution $\left(J_{\text {iso }}^{\text {DIP }}=\left(J_{\mathrm{x}}^{\text {DIP }}+J_{y}^{\text {DIP }}+J_{z}^{\text {DIP }}\right) / 3\right)$ of this AFM interaction was found of ca. $-0.05 \mathrm{~cm}^{-1}$, and can be readily understood by the relative collinear orientation of the easy magnetic axes as shown in Figure 3.

\section{Dynamic magnetic measurements}

A significant signal in absence of external magnetic field $\left(\mathrm{H}_{\mathrm{dc}}=0\right)$ is observed on DyAzo but in a high frequency region. This fast relaxation requires using a homemade ac probe able to reach ac field frequencies up to $70 \mathrm{KHz}$. The magnetic relaxation observed is almost temperature independent (Figure 4) and is a signature of quantum tunneling of the magnetization $\left(\tau_{2 \mathrm{~K}}=10 \mu \mathrm{s}\right)$. The distribution of the relaxation times is comprised between $\alpha_{2 \mathrm{~K}}=0.33$ and $\alpha_{5.8 \mathrm{~K}}=0.19$ (Figures S6-S7, Tables S5-S6). The relaxing fraction RF, (the amount of the sample that is able to relax slowly) can be estimated as RF= 1- $\left(\chi_{S} / \chi_{T}\right)$ were $\chi_{S}$ and $\chi_{T}$ are the adiabatic and isotherm susceptibility respectively. For DyAzO, RF is comprised between $82 \%$ and $66 \%$.

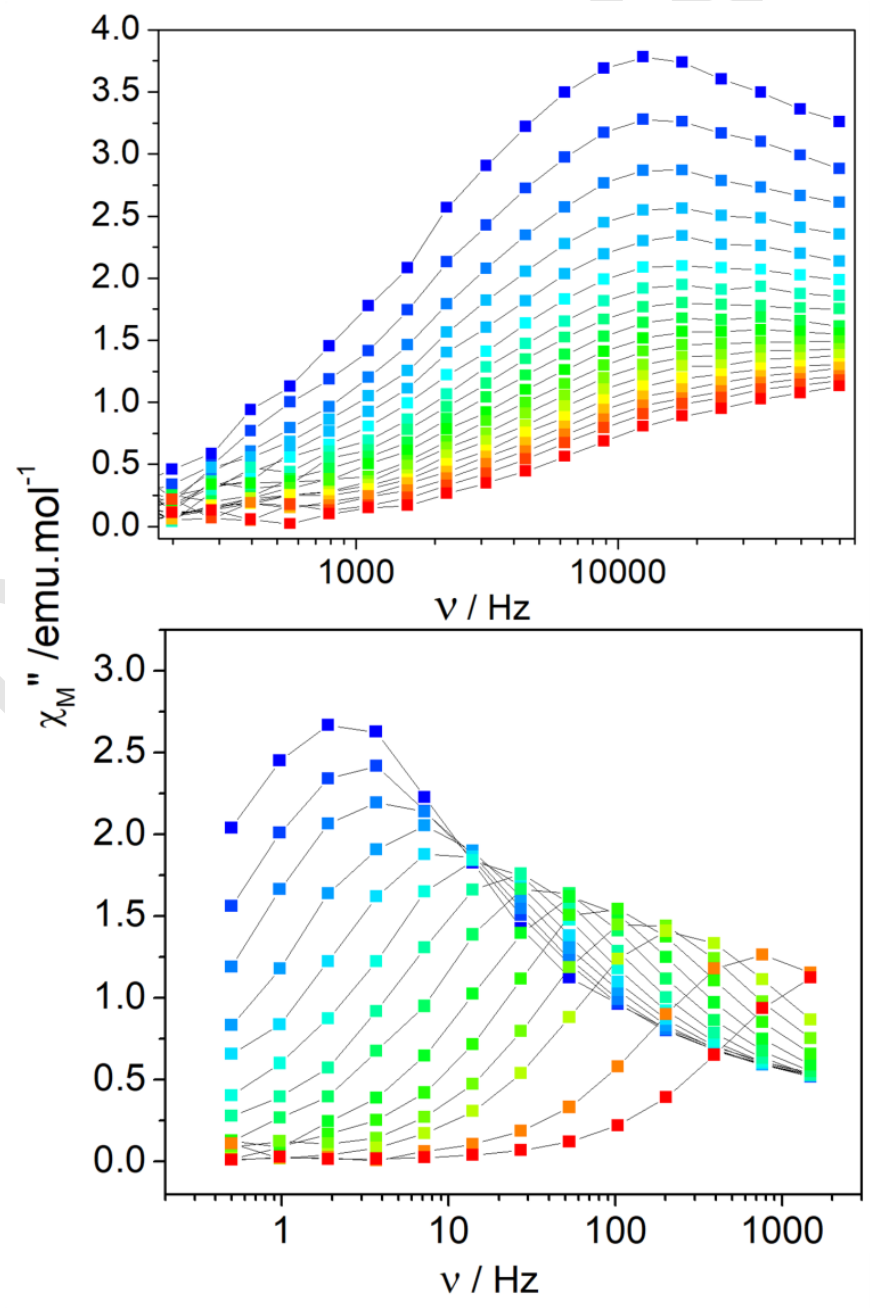

Figure 4. Frequency dependence of the out-of-phase component of the magnetization measured on DyAZO with $\mathrm{H}_{\mathrm{dc}}=0$ Oe, $1.6 \mathrm{~K}-7.6 \mathrm{~K}$ (top) and $\mathrm{H}_{\mathrm{dc}}=1200 \mathrm{Oe}, 1.8 \mathrm{~K}-5 \mathrm{~K}$ (bottom).

Field dependence of the dynamic magnetic susceptibility shows that the optimum magnetic field for magnetic slow relaxation is $H_{d c}=1200$ Oe (Figure S8), a common value for Dy-based SMMs. ${ }^{76}$ With this field, frequency dependence is observed in the $1.8-5 \mathrm{~K}$ temperature range in a standard frequency window $(1-1500 \mathrm{~Hz})$. Temperature dependence of 
the magnetic relaxation is much more pronounced than in zero field, with distributions of $\alpha_{2 k}=0.51$ and $\alpha_{4.5 K}=0.2$ with slightly optimized RF that is comprised between $89 \%$ and $72 \%$ (Figures S9-S10, Tables S7-S8).

In order to quantify the influence of the Dy-Dy magnetic coupling on DyAZO relaxation processes an isostructural $Y^{\prime \prime \prime}$-doped sample (latter named YDyAZO) was prepared (Figure S11). Its effective formula, determined on the basis of EDS measurement is $\left[\mathrm{Y}_{1.89} \mathrm{Dy} \mathrm{y}_{0.11}(\mathrm{AZO})_{6}(\mathrm{DMSO})_{2}\left(\mathrm{H}_{2} \mathrm{O}\right)_{2}\right] \cdot 4 \mathrm{DMSO}$ and thus it presents an experimental doping ratio of $5.5 \%$. This low Dy concentration ensures that most of the magnetic molecules are $\mathrm{Y}$-Dy ones and not Dy dimers.

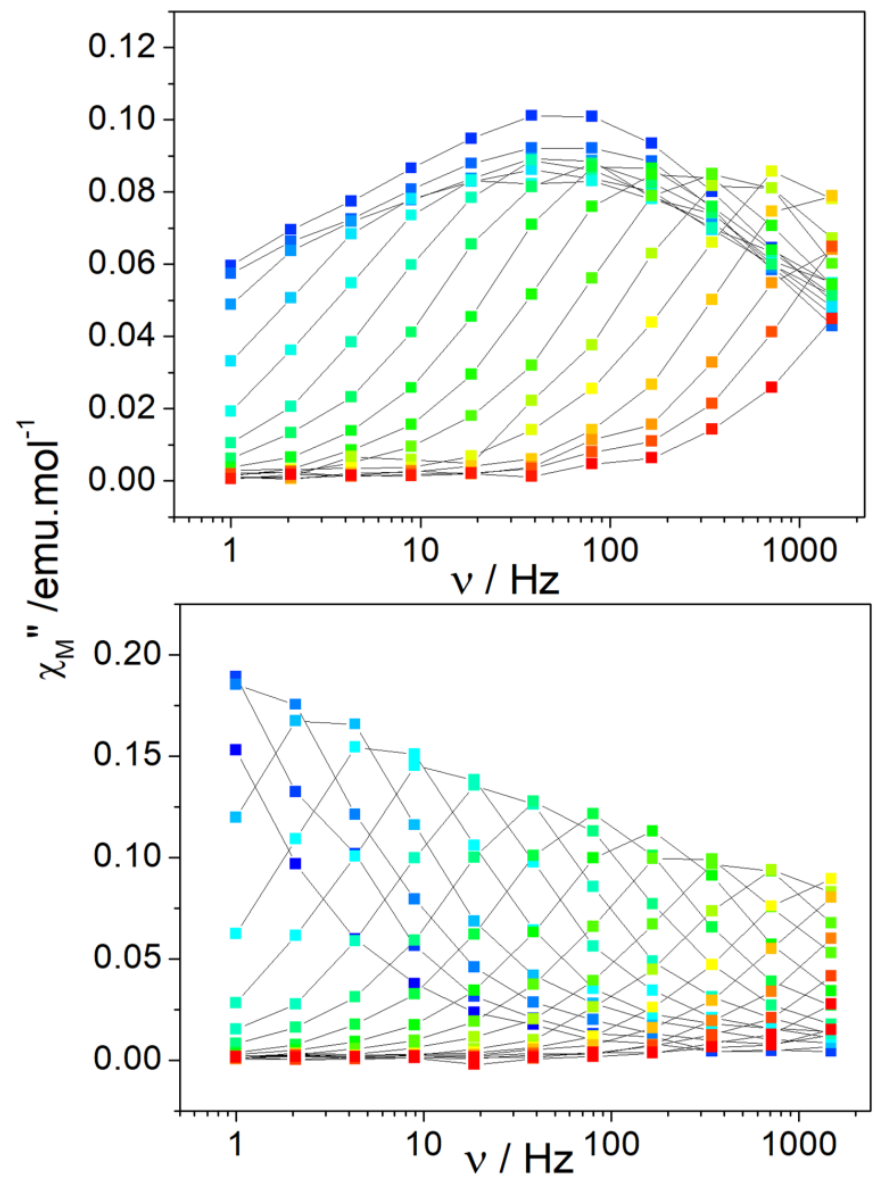

Figure 5. Frequency dependence of the out-of-phase component of the magnetization measured on YDyAZO with $\mathrm{H}_{\mathrm{dc}}=0 \mathrm{Oe}, 1.6 \mathrm{~K}-5 \mathrm{~K}$ (top) and $\mathrm{H}_{\mathrm{dc}}=1200 \mathrm{Oe}, 1.6 \mathrm{~K}-5 \mathrm{~K}$ (bottom).

Dynamic magnetic properties of YDyAZO were measured with $H_{d c}=0$ and $H_{d c}=1200$ Oe for easy comparison with DyAZO (Figure 5). The $Y^{\prime \prime \prime}$ doping efficiently suppresses zero-field fast relaxation (Figures S12-S14, Tables S9-S10) and relaxation times are slower than that of the pure compound. The distribution of the relaxation times increases $\left(\alpha_{2.3 \mathrm{~K}}=0.6\right.$ and $\alpha_{4.2 \mathrm{~K}}=0.14$ ) but the percentage of relaxing fraction is significantly enhanced (99\%-80\%). In field $\left(H_{d c}=1200 \mathrm{Oe}\right)$, this feature evolves in a similar way $\left(\alpha_{3.5 \mathrm{~K}}=0.11\right.$ and $\alpha_{4.7 \mathrm{~K}}=0.07$, relaxing fractions between $93-88 \%$ ) (Figures 5 , S15-S16 and Tables S11-S12).
Relaxation times can be fitted using the following equation (Figure 6): ${ }^{77,78}$

$\tau^{-1}=\tau_{\text {direct }}{ }^{-1}+\tau_{\text {tunnel }}{ }^{-1}+\tau_{\text {Raman }^{-1}}+\tau_{\text {Orbach }^{-1}}$ (1)

that gives:

$\tau^{-1}=\tau_{\text {direct }}{ }^{-1}+\tau_{\text {tunnel }}{ }^{-1}+B T^{n}+\tau_{0}^{-1} \exp \left(-U_{\text {eff }} / k_{B} T\right)$

where $T, \mathrm{U}_{\text {eff, }} \mathrm{B}$ and $\mathrm{n}$ are the temperature, the energy barrier for spin reversal and the Raman parameters respectively.

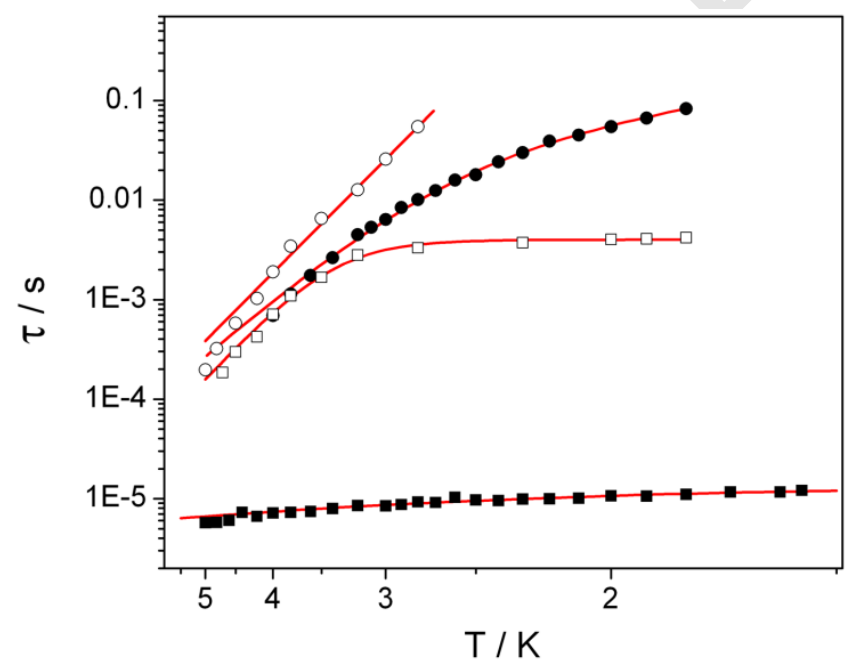

Figure 6. Relaxation times as a function of the temperature for DyAZO (filled symbols) and YDyAzO (empty symbols), measured with $H_{d c}=0$ Oe (squares) and $H_{d c}=1200$ Oe (circles). Red lines are the best fits discussed in the text.

In order to avoid over-parametrization that is very likely to occur on such systems, we have measured the field dependence of $\tau^{-1}$ of DyAZO . However no reliable fit could be obtained and this excludes the presence of direct relaxation in DyAzo.

Then, we have first fitted the in-field magnetic relaxation of the doped derivative YDyAZO $\left(\mathrm{H}_{\mathrm{dc}}=1200 \mathrm{Oe}\right)$ considering only an Orbach relaxation $\left(\tau_{0}=7.07 \times 10^{-7} \mathrm{~s}, U_{\text {eff }}=31.5 \mathrm{~K}\right)$. These values have been used as initial guess to fit $H_{d c}=0 \mathrm{Oe}$ measurement of YDyAZO $\mathrm{H}_{\mathrm{dc}}=0$ Oe. A tunneling relaxation that clearly occurs at low temperature $\left(\tau_{0}=1.82 \times 10^{-7} \mathrm{~s}\right.$, $\mathrm{U}_{\text {eff }}=34.0 \mathrm{~K}, \tau_{\text {tunnel }}=3.9810^{-3} \mathrm{~s}$ ) has been considered. With these values in mind, DyAZO $\mathrm{H}_{\mathrm{dc}}=1200 \mathrm{Oe}$, has been fitted and the addition of a Raman contribution to the relaxation has been necessary has commonly observed on Dy-SMMs ${ }^{77}$ $\left(\tau_{0}=1.07 \times 10^{-6} \mathrm{~s}, \mathrm{U}_{\text {eff }}=27.9 \mathrm{~K}, \mathrm{~B}=1.53 \mathrm{~s}^{-1} \cdot \mathrm{K}^{-1}, \mathrm{n}=3.50\right)$. Finally, on DyAzO $\mathrm{H}_{\mathrm{dc}}=0 \mathrm{Oe}$ almost full tunneling is observed $\left(\tau_{0}=5.25 \times 10^{-6} \mathrm{~s}, \mathrm{U}_{\text {eff }}=4.54 \mathrm{~K}, \tau_{\text {tunnel }}=1.35 \times 10^{-5} \mathrm{~s}\right)$.

On the basis of these values, it is clear that the fast relaxation observed on DyAzO is due to the Dy-Dy magnetic couplings but is also intrinsic to a given Dy" ion. This is confirmed theoretically with sizable calculated perpendicular EPR gfactors for the GS and first ESs, and almost perpendicular $\left(82^{\circ}\right)$ easy magnetic axes between the GS and the first ES, both phenomena favoring quantum tunneling of the magnetization. ${ }^{79}$ Indeed, the diamagnetic substitution is not 
enough to suppress all temperature independent relaxation in YDyAZO and external dc field is still necessary to reach a pure Orbach relaxation.

Hysteresis loops were measured at $0.5 \mathrm{~K}$ on DyAzO and YDyAZO with a field sweep rate of 15.5 Oe.s $^{-1}$ (Figure 7). No opening is seen on DyAzo but clear butterfly-like hysteresis is observed on YDyAZO, a curve shape that is commonly observed for Dy-SMMs. ${ }^{76}$ This hysteresis opening is ascribed to the suppression of the Dy-Dy magnetic couplings. ${ }^{80}$ However, as stated above, the doping is not enough to provide zero-field opening and zero-field fast relaxation remains intrinsic to a given Dy ${ }^{\prime \prime \prime}$ ion.

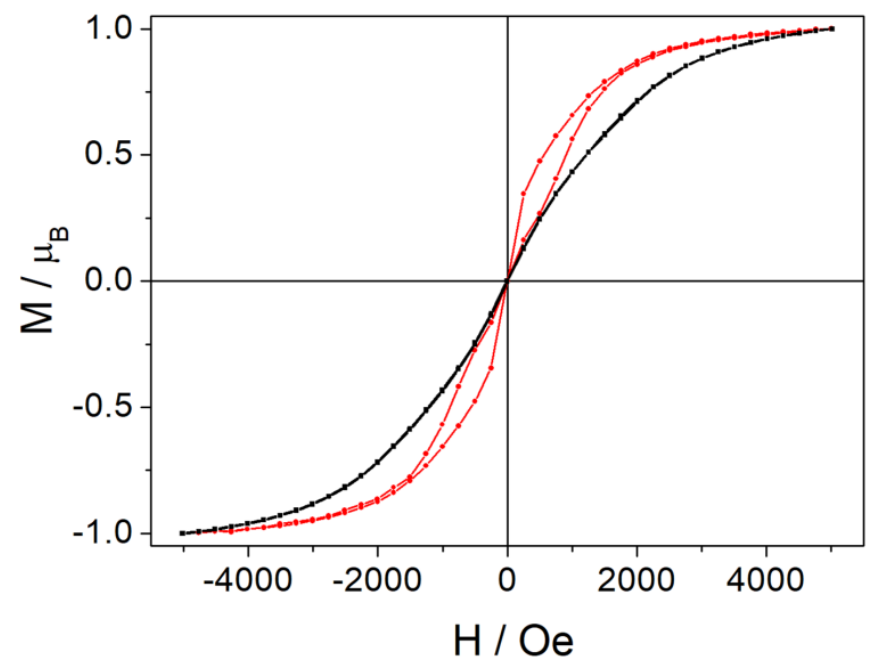

Figure 7. Hysteresis curves measured for DyAzO (black) and

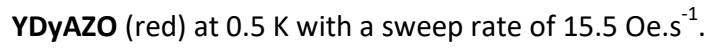

This strong effect of the intramolecular Ln"' couplings on the magnetic relaxation of $\mathrm{Ln}$ dimers is commonly observed. ${ }^{23,24}$, 26, 27, 80-92 One can note that the effect of $Y^{\prime \prime \prime}$ doping on this supramolecular chain (weak Dy-Dy interaction) is opposed to what observed by us and others on strongly coupled Dy ${ }^{\prime \prime \prime}$-chains, where Dy-Dy couplings significantly enhance the magnetic relaxation of a given Dy ${ }^{\text {III }}$ building block providing hysteresis with significant remnant magnetization. ${ }^{31,93}$

\section{Isomerization and magnetic studies in solution}

Azobenzene-like ligands are known to undergo trans-cis isomerization under UV irradiation. In solid-state, isomerization was not observed on single-crystals of DyAzo, probably because of their very strong absorption. Therefore similar attempts were performed on 1,4-dioxane solution of DyAzo $\left(1 \times 10^{-5} \mathrm{~mol}^{-1} \mathrm{~L}^{-1}\right.$, latter named DyAzO (liqu) $\left._{1}\right)$. Indeed, good solubility is observed in this solvent with no evidence of complex dissociation (Figure 8). Two broad and very intense absorption bands at $\lambda=330 \mathrm{~nm}\left(\pi-\pi^{*}\right)$ and $\lambda=440 \mathrm{~nm}\left(\mathrm{n}-\pi^{*}\right.$ transition) characteristic of azobenzene derivatives were observed. ${ }^{51}$ These bands are red-shifted when compared with the uncoordinated ligand AZO (Figure S17). Upon UV irradiation at $\lambda=365 \mathrm{~nm}$ with an irradiance $E_{e}=2.40 \mathrm{~mW} \cdot \mathrm{cm}^{-2}$ clear isomerization occurred and two isobestic points observed. Reversibility was obtained upon exposition to ambient light for one hour.

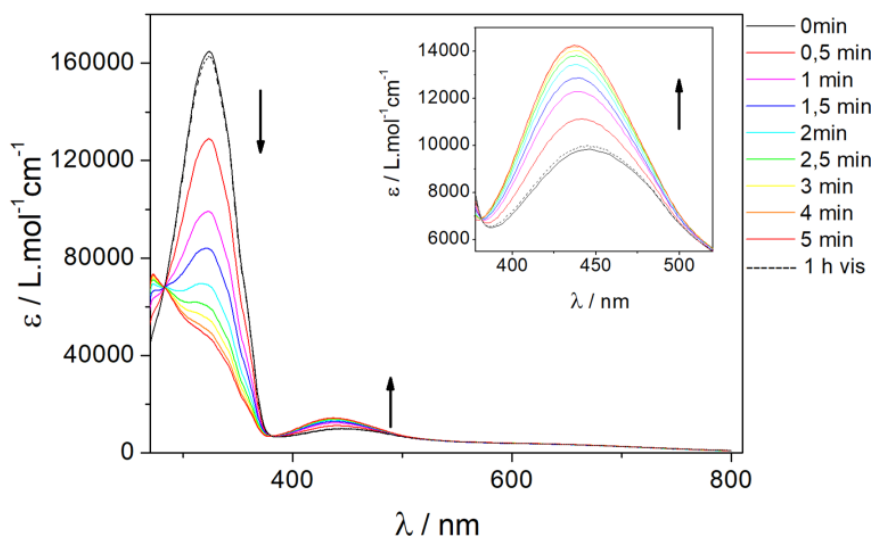

Figure 8. UV/Vis absorption spectra of a 1,4-dioxane solution $\left(1 \times 10^{-5} \mathrm{~mol}^{-\mathrm{L}^{-1}}\right)$ of DyAZO upon irradiation under UV light $\left(\lambda_{\text {exc }}=365 \mathrm{~nm}\right.$, irradiance $\left.E_{e}=2.40 \mathrm{~mW} . \mathrm{cm}^{-2}\right)$ and after 1 hour at ambient visible light.

Non-isomerized (trans) and isomerized (cis) DyAzO (liqu) solutions were characterized by dynamic magnetic

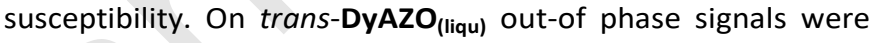
observed but with no clear maximums in the $1-1500 \mathrm{~Hz}$ frequency windows. The application of the external field $H_{d c}=1200$ Oe let the picture unchanged (Figure S18). Such degradation of the SMM properties when compared to solid-state is commonly observed ${ }^{46}$ and consequently only few examples of robust SMM behavior in solution are known. ${ }^{73,94}$ This could be due to different factors: i) The deformation of a given SMM as well as large geometric distribution in a sample upon solubilization ii) The evolution of the coordinated water molecule orientation when the supramolecular $\mathrm{H}$-bonded chain-like structure is destroyed by solubilization. In fact, extreme sensitivity of water molecule orientation ${ }^{95}, 96$ or $\mathrm{H}$-bonds on SMM behavior have been demonstrated. ${ }^{97}$ iii) The disappearance of the very small intermolecular dipolar interaction along the supramolecular chains that potentially enhanced SMM magnetic slow relaxation. This latter hypothesis is the less probable given the relative orientation of the Dy"I anisotropy axes and large intermolecular distances discussed above.

The cis-DyAZO $\mathbf{O}_{\text {(liqu) }}$ derivative has been characterized as well but unfortunately no clear evidence of a relaxation change upon isomerization was observed, possibly because these changes are visible only at very high frequencies (Figure S19). Accordingly, the slowly relaxing $Y^{\prime \prime \prime}$ doped analogues trans-YDyAZO (liqu) $_{\text {(liqu) }}$ and cis-YDyAZO $\mathbf{Y O}_{(\text {liqu }}$ were characterized (Figures S20-S21). Their magnetic signal is quite weak and noisy because of the very small amount of paramagnetic centers in these solutions. However, the $Y$ doping does not improve sufficiently the magnetic relaxation to draw a definitive conclusion. 


\section{Conclusions}

We report here a supramolecular chain of Dy-dimers decorated with azobenzene ligands (DyAZO). The Dy dimers behave as SMMs and as soon as the Dy-Dy intermolecular couplings are cancelled magnetic relaxation is enhanced. Indeed, magnetic hysteresis at $0.5 \mathrm{~K}$ is visible on YDyAZO. To the best of our knowledge only few examples of a SMM decorated with photochromic ligands have been reported so far. They deal with the two most iconic $3 \mathrm{~d}-\mathrm{SMMs}$, the $\mathrm{Mn}_{12}{ }^{98}$ and the $\mathrm{Fe}_{4} \cdot{ }^{99}$ On both SMMs very small modifications of the magnetic relaxation upon trans-cis isomerization was observed. 100, 101,41 This could be due to their strong intermolecular couplings that are very slightly affected by the isomerization of the decorating ligands. Since $4 \mathrm{f}-\mathrm{SMMs}$ are much more sensitive to small electrostatic changes in their surrounding an enhanced effect of the trans-cis isomerization could be expected on DyAzo. However, the absence of single-crystal to single-crystal isomerization forced us to work on 1,4-dioxane solutions. This solubilization induces an acceleration of the magnetic relaxation of DyAZO and YDyAZO that hampers the observation of magnetic relaxation modulation upon photo-isomerization. Consequently, our results suggest that Ln-SMMs with much more robust SMM behavior in solution need to be targeted in order to observe the switching of SMM behavior upon UV irradiation of photochromic ligands.

\section{Experimental}

\section{Synthesis}

Solvents (Sigma), ligands ( $\mathrm{TCl}$ chemicals) and lanthanides salts (AMPERE) were used as purchased. $0.3 \mathrm{mmol}$ of azobenzene-4-carboxylic acid (HAZO) were deprotonated by one equivalent $\mathrm{NaOH}$ in distilled water. Then $0.1 \mathrm{mmol}$ $\mathrm{DyCl}_{3} \cdot 6 \mathrm{H}_{2} \mathrm{O}$ salt was added to the aqueous solution and precipitation of an orange amorphous powder immediately occurs. The precipitates were filtered and washed with diethyl ether. In a second step, the dry precipitate was dissolved in the minimum amount of dimethylsulfoxide (DMSO). After ten days of slow evaporation at room-temperature, orange needle-shaped crystals of DyAZO were obtained (yield: 55\%). The doped YDyAZO was synthesized using the same procedure with the starting salts $\mathrm{DyCl}_{3} \cdot 6 \mathrm{H}_{2} \mathrm{O}$ and $\mathrm{YCl}_{3} \cdot 6 \mathrm{H}_{2} \mathrm{O}$ in a $19: 1$ molar ratio (yield: $45 \%$ ). As commonly observed a discrepancy between theoretical and experimental $Y^{\prime \prime \prime}$ content was found as observed on EDS measurements. ${ }^{31}$ Elemental analysis calcd (\%) for DyAZO, $\mathrm{C}_{82} \mathrm{H}_{70} \mathrm{~N}_{12} \mathrm{O}_{16} \mathrm{~S}_{2} \mathrm{Dy}_{2} \cdot \mathrm{C}_{4} \mathrm{H}_{12} \mathrm{~S}_{2} \mathrm{O}_{2}$ : C 51.01; $\mathrm{H} 4.08$; N 8.30; found C 52.8; H 3.91; N 8.60.

\section{Crystal structure determination}

A Single crystal was mounted on a APEX-II AXS-Bruker diffractometer equipped with a CCD camera and a graphite-monochromated MoK $\alpha$ radiation source $(\lambda=0.71073 \AA)$, from the Centre de Diffractométrie (CDFIX), Université de Rennes 1, France. Data were collected at $150 \mathrm{~K}$. Structure was solved with a direct method using the SIR-97 program $^{102}$ and refined with a full-matrix least-squares method on $\mathrm{F}^{2}$ using the SHELXL-97 program ${ }^{103}$ and WinGx interface. ${ }^{104}$ Crystallographic data are summarized in Table S1. CCDC1950517 contains the supplementary crystallographic data for this paper. These data can be obtained free of charge from The Cambridge Crystallographic Data Centre via www.ccdc.cam.ac.uk/data request/cif.

\section{Powder X-ray diffraction}

Diffractograms have been collected using a Panalytical X'Pert Pro diffractometer with an $X^{\prime}$ Celerator detector. The typical recording conditions were $45 \mathrm{kV}, 40 \mathrm{~mA}$ for $\mathrm{Cu}-\mathrm{K} \alpha$ $(\lambda=1.542 \AA)$, the diagrams were recorded in $\theta-\theta$ mode in 60 min between $5^{\circ}$ and $75^{\circ}$ ( 8378 measurements) with a step size of $0.0084^{\circ}$ and a scan time of $50 \mathrm{~s}$. The calculated patterns were produced using Mercury from CCDC.

\section{Magnetic measurements}

Magnetic dc-measurements were performed on polycrystalline sample embedded in grease to avoid in-field orientation of the crystallites. Low frequency $(1-1500 \mathrm{~Hz})$ ac measurements were performed on a Quantum Design MPMS magnetometer from "Centre de Mesures Physiques" of ISCR. High frequency ac measurements $(100-70000 \mathrm{~Hz})$ were performed using a homemade probe operating in an Oxford cryostat $^{105}$ from Laboratory of Molecular Magnetism (LaMM). All measurements were corrected for diamagnetic contribution with Pascal's constants. $1 \times 10^{-5} \mathrm{~mol} . \mathrm{L}^{-1}$ solutions of DyAZO and YDyAZO were irradiated in a dark chamber equipped with a UV lamp $\left(\lambda_{\text {exc }}=365 \mathrm{~nm}\right)$ that provides an irradiance of $\mathrm{E}_{\mathrm{e}}=2.40 \mathrm{~mW} \cdot \mathrm{cm}^{-1}$. Total photo-isomerization was assessed on the basis of the UV/Vis measurements depicted on Figure 8. Measurements of solutions were corrected from sample holder contribution and diamagnetic contribution of the 1,4-dioxane.

\section{Ab initio calculations}

As shown in Figure S5, the calculations were performed on a simplified structure of DyAZO where the six azobenzene-like ligands where simplified in order to decrease the computational cost of the WFT calculations. The hydrogen atom positions of the model compound were then optimized by using Kohn-Sham density functional theory (DFT) with the Amsterdam Density Functional $\left(\mathrm{ADF}^{106,107}\right)$ software package. This calculation utilized the scalar all-electron zeroth-order regular approximation $\left(\mathrm{ZORA}^{108}\right)$ along with the spinunrestricted formalism. The PBE ${ }^{109}$ functional (Perdew-BurkeErnzerhof) from the generalized gradient approximation, was employed along with the triple- $\zeta$ polarized Slater-type orbital (STO) all-electron basis set with two sets of polarization functions for all atoms $\left(\mathrm{TZ2P}^{110}\right)$.

The wavefunction theory (WFT) calculations were performed with the help of the Molcas 8.0. ${ }^{111}$ In these calculations, the complete active space self-consistent field ${ }^{112}$ (CASSCF) approach was used to treat the static correlation effects arising from the partially filled $4 f$ shell of the $\mathrm{Dy}^{3+}$ ion. The second-order Douglas-Kroll-Hess ${ }^{113}$ scalar relativistic (SR) 
Hamiltonian was used to treat the scalar relativistic effects in combination with the all-electron atomic natural orbital relativistically contracted (ANO-RCC) basis set from the Molcas library. ${ }^{114-117}$ The basis sets were contracted to the triple- $\zeta$ plus polarization (TZP) quality for the Dy, $O$ and bridging $C$ atoms $(D y=25 s 22 p 15 d 11 f 4 g 2 h / 8 s 7 p 4 d 3 f 2 g 1 h ; O, C=$ $14 s 9 p 5 d 3 f 2 g / 4 s 3 p 2 d 1 f$ ), to the double- $\zeta$ plus polarization (DZP) quality for the $S$ atoms ( $S=17 \mathrm{~s} 12 \mathrm{p} 5 \mathrm{~d} 4 \mathrm{f} 2 \mathrm{~g} / 4 \mathrm{~s} 3 \mathrm{p} 1 \mathrm{~d})$ and to the double- $\zeta$ quality for the $\mathrm{C}$ and $\mathrm{H}$ atoms $(\mathrm{H}=$ $8 \mathrm{~s} 4 \mathrm{p} 3 \mathrm{~d} 1 \mathrm{f} / 2 \mathrm{~s} ; \quad C=14 \mathrm{~s} 9 \mathrm{p} 5 \mathrm{~d} 3 \mathrm{f} 2 \mathrm{~g} / 3 \mathrm{~s} 2 \mathrm{p})$. The calculations employed the state-averaged formalism at the SR level by taking into account the 21 sextet, the 224 quartet and the 490 doublet spin states arising from the 9 electrons spanning the seven $4 f$ orbitals (i.e. CAS $(9,7)$ ). The spin-orbit coupling (SOC) was then introduced within a state interaction among the basis of calculated SR states using the restricted active space state interaction (RASSI) approach. ${ }^{114}$ Herein the SOC matrix is diagonalized using the calculated 21 SR sextet, 224 SR quartet and the $98^{\text {th }}$ lowest SR doublet spin states. The EPR $g$-factors were calculated according to Reference ${ }^{118}$ as implemented in the RASSI module of Molcas, whereas the magnetic susceptibility and magnetization calculations were performed using the Single-Aniso and Poly-aniso modules of Molcas as detailed in Reference. ${ }^{119}$

\section{Conflicts of interest}

There are no conflicts to declare.

\section{Acknowledgements}

This work was supported by INSA Rennes, CNRS and Chinese Scholarship Council (CSC). T.Roisnel and V. Dorcet are acknowledged for crystal structure data collection. K.B acknowledges the Institut Universitaire de France (IUF). Pr. A. Caneschi is acknowledged for instrumentation access. $\mathrm{Dr} \mathrm{L}$. Norel and Dr. J. Boixel are acknowledged for stimulating discussion. F.G. and B.L.G. thank the French GENCI/IDRIS-CINES centers for high-performance computing resources. F.G. and B.L.G. acknowledge the Stratégie d'Attractivité Durable (SAD18006 - LnCPLSMM) from Région Bretagne for financial support.

\section{Notes and references}

1 O. Kahn, Molecular Magnetism, Wiley-VCH, Weinheim, 1993.

2 J. Ferrando-Soria, J. Vallejo, M. Castellano, J. MartínezLillo, E. Pardo, J. Cano, I. Castro, F. Lloret, R. Ruiz-García and M. Julve, Coord. Chem. Rev., 2017, 339, 17-103.

3 D. Gatteschi, R. Sessoli and J. Villain, Molecular Nanomagnets, Oxford University Press, Oxford, 2006.

4 S. Gao, Molecular nanomagnets and related phenomena, Springer, 2015.
5 C. A. P. Goodwin, F. Ortu, D. Reta, N. F. Chilton and D. P. Mills, Nature, 2017, 548, 439-442.

6 F.-S. Guo, B. M. Day, Y.-C. Chen, M.-L. Tong, A. Mansikkamäki and R. A. Layfield, Science, 2018, 362, 1400-1403.

$7 \quad$ R. Layfield, F.-S. Guo, B. Day, Y.-C. Chen, M.-L. Tong and A. Mansikamäkki, Angew. Chem.-Int. Ed., 2017, 56, 1144511449.

$8 \quad$ K. Bernot, R. Sessoli, in Lanthanides and Actinides in Molecular Magnetism, Wiley-VCH Verlag GmbH \& Co. KGaA, 2015.

9 C. Benelli and D. Gatteschi, Introduction to Molecular Magnetism: From Transition Metals to Lanthanides, Wiley, 2015. 10 L. Sorace, C. Benelli and D. Gatteschi, Chem. Soc. Rev., 2011, 40, 3092-3104.

11 J. Luzon and R. Sessoli, Dalton Trans., 2012, 41, 1355613567.

12 Z. Zhu, M. Guo, X.-L. Li and J. Tang, Coord. Chem. Rev., 2019, 378, 350-364.

13 M. A. Sørensen, U. B. Hansen, M. Perfetti, K. S. Pedersen, E. Bartolomé, G. G. Simeoni, H. Mutka, S. Rols, M. Jeong, I. Zivkovic, M. Retuerto, A. Arauzo, J. Bartolomé, S. Piligkos, H. Weihe, L. H. Doerrer, J. van Slageren, H. M. Rønnow, K. Lefmann and J. Bendix, Nat. Commun., 2018, 9, 1292.

14 H. Bolvin, R. Alessandri, H. Zulfikri and J. Autschbach, Chem. Eur. J., 2018, 24, 5538-5550.

15 C. Bosch-Navarro, E. Coronado, C. Martí-Gastaldo, B. Rodríguez-González and L. M. Liz-Marzán, Adv. Funct. Mater., 2012, 22, 979-988.

16 J. Jung, F. Le Natur, O. Cador, F. Pointillart, G. Calvez, C. Daiguebonne, O. Guillou, T. Guizouarn, B. Le Guennic and K. Bernot, Chem. Commun., 2014, 50, 13346-13348.

17 W.-B. Sun, P.-F. Yan, S.-D. Jiang, B.-W. Wang, Y.-Q. Zhang, H.-F. Li, P. Chen, Z.-M. Wang and S. Gao, Chem. Sci., 2016, 7, 684-691.

18 S. K. Singh, B. Pandey, G. Velmurugan and G. Rajaraman, Dalton Trans., 2017, 46, 11913-11924.

19 K. Prša, J. Nehrkorn, J. Corbey, W. Evans, S. Demir, J. Long, T. Guidi and O. Waldmann, Magnetochemistry, 2016, 2, 45.

20 K. S. Pedersen, L. Ungur, M. Sigrist, A. Sundt, M. SchauMagnussen, V. Vieru, H. Mutka, S. Rols, H. Weihe, O. Waldmann, L. F. Chibotaru, J. Bendix and J. Dreiser, Chem. Sci., 2014, 5, 1650-1660.

21 F. Habib and M. Murugesu, Chem. Soc. Rev., 2013, 42, 3278-3288.

22 X. Yi, F. Pointillart, B. Le Guennic, J. Jung, C. Daiguebonne, G. Calvez, O. Guillou and K. Bernot, Polyhedron, 2019, 164, 41-47.

23 G. Huang, X. Yi, J. Jung, O. Guillou, O. Cador, F. Pointillart, B. Le Guennic and K. Bernot, Eur. J. Inorg. Chem., 2018, 326-332.

24 I. Cimatti, X. Yi, R. Sessoli, M. Puget, B. L. Guennic, J. Jung, T. Guizouarn, A. Magnani, K. Bernot and M. Mannini, Appl. Surf. Sci., 2018, 432, 7-14.

25 X. Yi, G. Calvez, C. Daiguebonne, O. Guillou and K. Bernot, Inorg. Chem., 2015, 54, 5213-5219. 
X. Yi, K. Bernot, O. Cador, J. Luzon, G. Calvez, C. Daiguebonne and O. Guillou, Dalton Trans., 2013, 42, 67286731.

27 X. Yi, K. Bernot, F. Pointillart, G. Poneti, G. Calvez, C. Daiguebonne, O. Guillou and R. Sessoli, Chem.-Eur. J., 2012, 18 11379-11387.

28 N. F. Chilton, D. Collison, E. J. L. Mclnnes, R. E. P. Winpenny and A. Soncini, Nat. Commun., 2013, 4, 2551.

29 S.-D. Jiang and S.-X. Qin, Inorg. Chem. Front., 2015, 2, 613-619.

30 J. Jung, X. Yi, G. Huang, G. Calvez, C. Daiguebonne, O. Guillou, O. Cador, A. Caneschi, T. Roisnel, B. Le Guennic and K. Bernot, Dalton Trans., 2015, 44, 18270-18275.

31 G. Huang, G. Fernandez-Garcia, I. Badiane, M. Camara, S. Freslon, O. Guillou, C. Daiguebonne, F. Totti, O. Cador, T. Guizouarn, B. Le Guennic and K. Bernot, Chem. Eur. J., 2018, 24, 6983-6991.

32 D. Pinkowicz, H. I. Southerland, C. Avendaño, A. Prosvirin, C. Sanders, W. Wernsdorfer, K. S. Pedersen, J. Dreiser, R. Clérac, J. Nehrkorn, G. G. Simeoni, A. Schnegg, K. Holldack and K. R. Dunbar, J. Am. Chem. Soc., 2015, 137, 14406-14422.

33 D. Shao, L. Shi, L. Yin, B.-L. Wang, Z.-X. Wang, Y.-Q. Zhang and X.-Y. Wang, Chem. Sci., 2018, 9, 7986-7991.

34 A. Witt, F. W. Heinemann and M. M. Khusniyarov, Chem. Sci., 2015, 6, 4599-4609.

35 W. Jiang, C. Jiao, Y. Meng, L. Zhao, Q. Liu and T. Liu, Chem. Sci., 2018, 9, 617-622.

$36 \mathrm{X}$. Feng, C. Mathonière, I.-R. Jeon, M. Rouzières, A. Ozarowski, M. L. Aubrey, M. I. Gonzalez, R. Clérac and J. R. Long, J. Am. Chem. Soc., 2013, 135, 15880-15884.

37 B. Doistau, L. Benda, B. Hasenknopf, V. Marvaud and G. Vives, Magnetochemistry, 2018, 4, 5.

38 A. Mondal, Y. Li, M. Seuleiman, M. Julve, L. Toupet, M. Buron-Le Cointe and R. Lescouëzec, J. Am. Chem. Soc., 2013, 135, 1653-1656.

39 C. M. Dickie, A. L. Laughlin, J. D. Wofford, N. S. Bhuvanesh and M. Nippe, Chem. Sci., 2017, 8, 8039-8049.

40 A. Fetoh, G. Cosquer, M. Morimoto, M. Irie, O. ElGammal, G. A. El-Reash, B. K. Breedlove and M. Yamashita, Scientific Reports, 2016, 6, 23785.

41 T. K. Prasad, G. Poneti, L. Sorace, M. J. RodriguezDouton, A.-L. Barra, P. Neugebauer, L. Costantino, R. Sessoli and A. Cornia, Dalton Trans., 2012, 41, 8368-8378.

42 K. Suzuki, R. Sato and N. Mizuno, Chem. Sci., 2013, 4, 596-600.

43 Q. Zhou, F. Yang, B. J. Xin, G. Zeng, X. J. Zhou, K. Liu, D. X. Ma, G. H. Li, Z. Shi and S. H. Feng, Chem. Commun., 2013, 49, 8244-8246.

44 M. Gonidec, F. Luis, À. Vílchez, J. Esquena, D. B. Amabilino and J. Veciana, Angew. Chem.-Int. Ed., 2010, 49, 16231626.

45 L. Norel, M. Feng, K. Bernot, T. Roisnel, T. Guizouarn, K. Costuas and S. Rigaut, Inorg. Chem., 2014, 53, 2361-2363.

46 P. Selvanathan, V. Dorcet, T. Roisnel, K. Bernot, G. Huang, B. Le Guennic, L. Norel and S. Rigaut, Dalton Trans., 2018, 47, 4139-4148.
47 G. Cosquer, M. Kamila, Z.-Y. Li, B. Breedlove and M. Yamashita, Inorganics, 2018, 6, 9.

48 G. Cosquer, M. Morimoto, M. Irie, A. Fetoh, B. K. Breedlove and M. Yamashita, Dalton Trans., 2015, 44, 59966002.

49 D. Pinkowicz, M. Ren, L.-M. Zheng, S. Sato, M. Hasegawa, M. Morimoto, M. Irie, B. K. Breedlove, G. Cosquer, K. Katoh and M. Yamashita, Chem. Eur. J., 2014, 20, 12502-12513.

50 W.-W. He, S.-L. Li and Y.-Q. Lan, Inorg. Chem. Front., 2018, 5, 279-300.

51 H. M. D. Bandara and S. C. Burdette, Chem. Soc. Rev., 2012, 41, 1809-1825.

52 M. Kurihara and H. Nishihara, Coord. Chem. Rev., 2002, 226, 125-135.

53 B. Y. Choi, S. J. Kahng, S. Kim, H. Kim, H. W. Kim, Y. J. Song, J. Ihm and Y. Kuk, Phys. Rev. Lett., 2006, 96, 4.

54 F. Leyssner, S. Hagen, L. Ovari, J. Dokic, P. Saalfrank, M. V. Peters, S. Hecht, T. Klamroth and P. Tegeder, J. Phys. Chem. C, 114, 1231-1239.

55 B.-Y. Choi, S.-J. Kahng, S. Kim, H. Kim, H. W. Kim, Y. J. Song, J. Ihm and Y. Kuk, Phys. Rev. Lett., 2006, 96, 156106.

56 F. Leyssner, S. Hagen, L. Óvári, J. Dokić, P. Saalfrank, M. V. Peters, S. Hecht, T. Klamroth and P. Tegeder, J. Phys. Chem. C, 2010, 114, 1231-1239.

57 E. Merino and M. Ribagorda, Beilstein J. Org. Chem., 2012, 8, 1071-1090.

58 T. Muraoka, K. Kinbara, Y. Kobayashi and T. Aida, J. Am. Chem. Soc., 2003, 125, 5612-5613.

59 H. Koshima, N. Ojima and H. Uchimoto, J. Am. Chem. Soc., 2009, 131, 6890-6891.

60 Y.-G. Wang, Y.-Q. Li, H.-H. Tang, L.-R. Lin and L.-H. Ma, ACS Omega, 2018, 3, 5480-5490.

61 T. Muraoka, K. Kinbara and T. Aida, Nature, 2006, 440,

512.

62 S. Venkataramani, U. Jana, M. Dommaschk, F. D. Sönnichsen, F. Tuczek and R. Herges, Science, 2011, 331, 445448.

63 J. Moreno, L. Grubert, J. Schwarz, D. Bléger and S. Hecht, Chem. Eur. J., 2017, 23, 14090-14095.

64 M. Kurihara, T. Matsuda, A. Hirooka, T. Yutaka and H. Nishihara, J. Am. Chem. Soc., 2004, 126, 4740-4740.

65 T. Yutaka, I. Mori, M. Kurihara, J. Mizutani, K. Kubo, S. Furusho, K. Matsumura, N. Tamai and H. Nishihara, Inorg. Chem., 2001, 40, 4986-4995.

66 V. Guerchais and H. Le Bozec, in Molecular Organometallic Materials for Optics, eds. V. Guerchais and H. Le Bozec, Springer-Verlag Berlin Heidelberg, 2010, pp. 171-225.

67 J. Park, L.-B. Sun, Y.-P. Chen, Z. Perry and H.-C. Zhou, Angew. Chem.-Int. Ed., 2014, 53, 5842-5846.

68 H.-J. Timpe, Journal für Praktische Chemie, 1991, 333, $811-812$.

69 L. R. Lin, X. Wang, G. N. Wei, H. H. Tang, H. Zhang and L. H. Ma, Dalton Trans., 2016, 45, 14954-14964.

70 L.-R. Lin, H.-H. Tang, Y.-G. Wang, X. Wang, X.-M. Fang and L.-H. Ma, Inorg. Chem., 2017, 56, 3889-3900.

71 S. Alvarez, P. Alemany, D. Casanova, J. Cirera, M. Llunell and D. Avnir, Coord. Chem. Rev., 2005, 249, 1693-1708. 


\section{3, 257, 1728-1763.}

74 I. Mylonas-Margaritis, J. Mayans, S.-M. Sakellakou, C. P. Raptopoulou, V. Psycharis, A. Escuer and S. P. Perlepes, Magnetochemistry, 2017, 3, 5.

75 M. Perfetti, M. Gysler, Y. Rechkemmer-Patalen, P Zhang, H. Taştan, F. Fischer, J. Netz, W. Frey, L. W. Zimmermann, T. Schleid, M. Hakl, M. Orlita, L. Ungur, L. Chibotaru, T. BrockNannestad, S. Piligkos and J. van Slageren, Chem. Sci., 2019, 10, 2101-2110.

76 D. N. Woodruff, R. E. P. Winpenny and R. A. Layfield, Chem. Rev., 2013, 113, 5110-5148.

77 J.-L. Liu, Y.-C. Chen and M.-L. Tong, Chem. Soc. Rev. 2018, 47, 2431-2453.

78 S. T. Liddle and J. van Slageren, Chem. Soc. Rev., 2015, 44, 6655-6669.

79 L. Ungur and L. F. Chibotaru, Phys. Chem. Chem. Phys 2011, 13, 20086-20090.

80 E. Moreno Pineda, N. F. Chilton, R. Marx, M. Dörfel, D. O. Sells, P. Neugebauer, S.-D. Jiang, D. Collison, J. van Slageren, E. J. L. Mclnnes and R. E. P. Winpenny, Nat Commun, 2014, 5, 5243.

81 C. Y. Chow, H. Bolvin, V. E. Campbell, R. Guillot, J. W. Kampf, W. Wernsdorfer, F. Gendron, J. Autschbach, V. L. Pecoraro and T. Mallah, Chem. Sci., 2015, 6, 4148-4159.

82 X. Zhang, N. Xu, W. Shi, B.-W. Wang and P. Cheng, Inorg. Chem. Front., 2018, 5, 432-437.

83 H.-R. Tu, W.-B. Sun, H.-F. Li, P. Chen, Y.-M. Tian, W.-Y. Zhang, Y.-Q. Zhang and P.-F. Yan, Inorg. Chem. Front., 2017, 4, 499-508.

84 J. D. Hilgar, B. S. Flores and J. D. Rinehart, Chem. Commun., 2017, 53, 7322-7324.

85 F. Pointillart, Y. Le Gal, S. Golhen, O. Cador and L. Ouahab, Chem. Eur. J., 2011, 17, 10397-10404.

86 J. Long, F. Habib, P. H. Lin, I. Korobkov, G. Enright, L. Ungur, W. Wernsdorfer, L. F. Chibotaru and M. Murugesu, J. Am. Chem. Soc., 2011, 133, 5319-5328.

87 M. Guo, Y.-Q. Zhang, Z. Zhu and J. Tang, Inorg. Chem., 2018, 57, 12213-12221.

88 L. Zhang, Y.-Q. Zhang, P. Zhang, L. Zhao, M. Guo and J. Tang, Inorg. Chem., 2017, 56, 7882-7889.

89 K. Zhang, D. Liu, V. Vieru, L. Hou, B. Cui, F.-S. Guo, L. F. Chibotaru and Y.-Y. Wang, Dalton Trans., 2017, 46, 638-642.

90 M. Guo, Y. Xu, J. Wu, L. Zhao and J. Tang, Dalton Trans., $2017,46,8252-8258$.

91 P. Comba, M. Großhauser, R. Klingeler, C. Koo, Y. Lan, D. Müller, J. Park, A. Powell, M. J. Riley and H. Wadepohl, Inorg. Chem., 2015, 54, 11247-11258.

92 H. Tian, L. Ungur, L. Zhao, S. Ding, J. Tang and L. F. Chibotaru, Chem. Eur. J., 2018, 24, 9928-9939.

93 X. Zhang, S. Liu, V. Vieru, N. Xu, C. Gao, B. W. Wang, W. Shi, L. F. Chibotaru, S. Gao, P. Cheng and A. K. Powell, Chem. Eur. J., 2018, 24, 6079-6086.

94 T. T. da Cunha, J. Jung, M. E. Boulon, G. Campo, F. Pointillart, C. L. M. Pereira, B. Le Guennic, O. Cador, K. Bernot, F.
Pineider, S. Golhen and L. Ouahab, J. Am. Chem. Soc., 2013, 135, 16332-16335.

95 M. Briganti, G. F. Garcia, J. Jung, R. Sessoli, B. Le Guennic and F. Totti, Chem. Sci., 2019, 10, 7233-7245.

96 G. Cucinotta, M. Perfetti, J. Luzon, M. Etienne, P.-E. Car, A. Caneschi, G. Calvez, K. Bernot and R. Sessoli, Angew. Chem.Int. Edit., 2012, 51, 1606-1610.

97 J. Jung, O. Cador, K. Bernot, F. Pointillart, J. Luzon and B. Le Guennic, Beilstein J. Nanotechnol., 2014, 5, 2267-2274.

98 R. Bagai and G. Christou, Chem. Soc. Rev., 2009, 38, 1011-1026.

99 A. Cornia, M. Mannini, R. Sessoli and D. Gatteschi, Eur. J. Inorg. Chem., 2019, 552-568.

100 S. George and J. Kim, Bull. Korean Chem. Soc., 2009, 30, 1143-1146.

101 T. Akitsu, C. Ishioka and T. Itoh, Cent. Eur. J. Chem., 2009, 7, 690 .

102 A. Altomare, M. C. Burla, M. Camalli, G. L. Cascarano, C. Giacovazzo, A. Guagliardi, A. G. G. Moliterni, G. Polidori and R. Spagna, J. Appl. Crystallogr., 1999, 32, 115-119.

103 G. M. Sheldrick and T. R. Schneider, Methods Enzymol., 1997, 277, 319-343.

104 L. J. Farrugia, J. Appl. Crystallogr., 1999, 32, 837-838.

105 S. Midollini, A. Oriandini, P. Rosa and L. Sorace, Inorg. Chem., 2005, 44, 2060-2066.

106 G. te Velde, F. M. Bickelhaupt, E. J. Baerends, C. Fonseca Guerra, S. J. A. van Gisbergen, J. G. Snijders and T. Ziegler, J. Comput. Chem., 2001, 22, 931-967.

107 C. Fonseca Guerra, J. G. Snijders, G. te Velde and E. J. Baerends, Theor. Chem. Acc., 1998, 99, 391-403.

108 E. v. Lenthe, E. J. Baerends and J. G. Snijders, J. Chem. Phys., 1993, 99, 4597-4610.

109 J. P. Perdew, K. Burke and M. Ernzerhof, Phys. Rev. Lett., 1996, 77, 3865-3868.

110 E. Van Lenthe and E. J. Baerends, J. Comput. Chem., 2003, 24, 1142-1156.

111 F. Aquilante, J. Autschbach, R. K. Carlson, L. F. Chibotaru, M. G. Delcey, L. De Vico, I. Fdez. Galván, N. Ferré, L. M. Frutos, L. Gagliardi, M. Garavelli, A. Giussani, C. E. Hoyer, G. Li Manni, H. Lischka, D. Ma, P. Å. Malmqvist, T. Müller, A. Nenov, M. Olivucci, T. B. Pedersen, D. Peng, F. Plasser, B. Pritchard, M. Reiher, I. Rivalta, I. Schapiro, J. Segarra-Martí, M. Stenrup, D. G. Truhlar, L. Ungur, A. Valentini, S. Vancoillie, V. Veryazov, V. P. Vysotskiy, O. Weingart, F. Zapata and R. Lindh, J. Comput. Chem., 2015, 37, 506-541.

112 B. O. Roos, P. R. Taylor and P. E. M. Siegbahn, Chem.Phys., 1980, 48, 157-173.

113 A. Wolf, M. Reiher and B. A. Hess, J. Chem. Phys., 2002, 117, 9215-9226.

114 P. A.. Malmqvist, B. O. Roos and B. Schimmelpfennig, Chem. Phys. Lett, 2002, 357, 230-240.

115 B. O. Roos, R. Lindh, P. Å. Malmqvist, V. Veryazov and P. O. Widmark, J. Phys. Chem. A, 2005, 109, 6575-6579.

116 B. O. Roos, R. Lindh, P.-Å. Malmqvist, V. Veryazov and P.-O. Widmark, J. Phys. Chem. A, 2004, 108, 2851-2858.

117 P. O. Widmark, P. Å. Malmqvist and B. O. Roos, Theor. Chim. Acta, 1990, 77, 291-306. 
H. Bolvin, ChemPhysChem, 2006, 7, 1575-1589.

119 L. F. Chibotaru and L. Ungur, J. Chem. Phys., 2012, 137,

064112. 